\title{
Apogeo y declive de ansí en los Siglos de Oro: nuevos datos desde la sociolingüística histórica
}

\author{
José Luis Blas Arroyo ${ }^{1}$ \\ Universitat Jaume I, España
}

\begin{abstract}
Resumen
A partir de un corpus compuesto íntegramente por textos de inmediatez comunicativa, el presente estudio analiza un fenómeno de variación que enfrentó a los adverbios así y ansí durante los Siglos de Oro. En el marco de la sociolingüística histórica, el análisis de regresión logística de efectos mixtos efectuado muestra que la forma vernácula ansí gozó de un considerable éxito durante buena parte de este periodo, si bien conoció un momento culminante entre $1540 \mathrm{y}$ 1620. Sin embargo, a partir de entonces, los usos del adverbio irían descendiendo bruscamente hasta cerrar la centuria con empleos que hacían presagiar ya la censura a la que el adverbio iba a ser sometido a partir del siglo XVIII. Otro resultado relevante es que, en la difusión de ansí, cobraron especial importancia algunos factores extralingüísticos en mucha mayor medida que los lingüísticos, un hecho poco habitual entre las variables gramaticales, aunque explicable en este caso por el componente morfo-léxico que presenta este hecho de variación. Los factores más destacados fueron de carácter dialectal -la principal distribución de la forma vernácula
\end{abstract}

1 Para correspondencia, dirigirse a: José Luis Blas Arroyo (blas@fil.uji.es), Facultad de Ciencias Humanas y Sociales / Universitat Jaume I; 12071 Avenida Sos Baynat s/n. Castellón (España). ORCID 0000-0002-6700-0668. 
tuvo lugar en las áreas centro-meridionales de la Península, así como en las comunidades americanas-y sociolectal, con una preferencia mayor por ansí entre los estratos bajos, seguidos por los intermedios y a distancia de las élites, las cuales se mostraron siempre más reacias a su empleo, especialmente a partir del siglo XVII.

Palabras clave: sociolingüística histórica, variación y cambio lingüístico, alternancia ansí/así, Siglos de Oro, español.

\title{
The Rise AND fall of ansí In Golden Age Spanish: NeW Data FROM THE PERSPECTIVE OF HISTORICAL SOCIOLINGUISTICS
}

\begin{abstract}
Based on a corpus of communicative immediacy texts, the present study analyzes the variation between the adverbs ansi and as $i$ during the Golden Age Spanish period. Within the framework of historical sociolinguistics, the mixed-effects logistic regression analysis carried out shows that the vernacular form ansi enjoyed considerable success during this period, although it reached its peak between 1540 and 1620. However, from the latter date onwards, the uses of the adverb declined sharply until the end of the century, foreshadowing the negative attitudes to which ansi was exposed from the 18th century onwards. Another meaningful result of the study is that, in the diffusion of ansi, some extralinguistic factors took on special relevance to a much greater extent than the linguistic ones, an unusual fact among grammatical variables, perhaps explainable in this case by the important morpho-lexical component that this variation represents. The most relevant factors were of a dialectal -the main distribution of the vernacular form took place in the central-southern areas of Spain, as well as in the American speech communities- and sociolectal nature, with a greater preference for ansi among the lower strata, followed by the intermediate ones, and both of them a long way from the social elites. These elites were always more reluctant to use the vernacular form, especially from the middle of the Seventeenth century onwards.
\end{abstract}

Keywords: Historical sociolinguistics, language variation and change, ansíasi variation, Golden Age, Spanish.

Recibido: 04/09/20 Aceptado: 23/03/21 


\section{INTRODUCCIÓN ${ }^{2}$}

En el marco de la sociolingüística histórica, en este trabajo presentamos los principales resultados de un estudio acerca de un fenómeno de variación que tuvo una notable vitalidad durante el español de los Siglos de Oro. Nos referimos a la alternancia ente los adverbios así, forma más frecuente en la historia del español, y ansí, una variante que, si bien hunde sus raíces en la Edad Media, alcanzó un especial esplendor durante el periodo analizado en estas páginas. Los dos ejemplos siguientes son representativos de esa variación, que pudo estar presente incluso en el habla de los mismos individuos, como revela el uso alternativo de ambas formas en una misma carta enviada desde América por un emigrante español del siglo XVI a su destinatario en Sevilla:

(1) por munchas cartas que a vm tengo escrit's asi del nuebo reyno de granada donde vm sabe que yo vine encaminado quando despaña sali... (Cartas de particulares en Indias, 1569)

(2) ... y si no le obieren dado estudio como diho tengo quyero que los adreçen de vn vestido de camino y otro de rua onrosos y vn cavallo y ansi se los entreguen al diho ant ${ }^{\circ}$ de quinones para que los llebe consigo a la corte (Cartas de particulares en Indias, 1569)

\footnotetext{
2 El presente estudio forma parte del proyecto de investigación "Dimensiones estructurales, sociales e idiolectales del cambio lingüístico: nuevas aportaciones desde la sociolingüística histórica al estudio del español", financiado por el Ministerio de Economía y Competitividad (2018-2021) (Ref. FFI2017-86194-P). Desde estas líneas, quisiera agradecer a Carme Barberà, María Chiara Marullo, Jordi Ayza, Javier Lara y Brittani Cortés por su valiosa colaboración en el Laboratorio de Sociolingüística de la Universitat Jaume I, especialmente en la preparación de los textos que integran el corpus. Asimismo, agradezco los perspicaces comentarios de dos evaluadores anónimos a una versión previa del artículo. Cualquier error que persista en el texto es de mi entera responsabilidad.

Aunque todas las ediciones recogidas en el corpus señalan haber respetado el texto original de los documentos (ver más adelante § 4), somos conscientes de que las intervenciones llevadas a cabo en aspectos tales como la puntuación, la acentuación, las abreviaturas, el empleo de mayúsculas, etc. hacen que, en los ejemplos que se muestran a lo largo del trabajo, aparezcan discrepancias de presentación. Aun así, y tras corregir algunas incongruencias advertidas por uno de los evaluadores anónimos del artículo - a quien agradecemos sinceramente su advertencia- hemos decidido mantener básicamente las transcripciones tal como aparecen en los textos, obviando así una labor filológica, sin duda, interesante, pero que está más allá de nuestros actuales propósitos.
} 
El español clásico fue especialmente pródigo en fenómenos de variación gramatical (Girón Alconchel 2004). En él asistimos a la decadencia de antiguas variantes procedentes del periodo medieval, que en muchos casos no traspasarían los límites del siglo XVI, pero también al triunfo de otras nuevas, que vendrían a disputar la primacía a formas más tradicionales. Incluso no faltan los ejemplos de variantes cuya competencia iba a superar los límites de este periodo, para extenderse a fases posteriores en la historia del español, aunque, por lo general, con una correlación de fuerzas ya diferente. Sin embargo, y como tendremos ocasión de comprobar, el fenómeno analizado aquí presenta algunas singularidades dignas de atención, sobre todo por dos motivos: las etapas evolutivas abruptas por las que atravesó, y el hecho de haberse visto condicionado por factores extralingüísticos antes que lingüísticos, un desenlace poco habitual entre las variables gramaticales. Ello, unido a la escasez de trabajos sobre el tema, especialmente sobre su dimensión sociolingüística, justifica el interés por un hecho de variación cuyo análisis minucioso es ya posible en la actualidad mediante el concurso de corpus de inmediatez comunicativa suficientemente amplios y representativos de todo el espectro social, y que nos acercan, probablemente como ningún otro género, a la oralidad de tiempos pretéritos.

La estructura del artículo queda como sigue. En el siguiente apartado revisamos los principales hitos históricos y dialectales de la variable lingüística a la luz de la bibliografía disponible. En la sección § 3, repasamos e ilustramos, con ejemplos extraídos del corpus, los principales usos que los adverbios -y, en particular, ansí, sobre el que ponemos el foco de atención- exhiben en el español clásico, así como la identificación de los factores lingüísticos y extralingüísticos que se han considerado en el estudio cuantitativo. Los principales detalles metodológicos acerca de este último, así como los relativos al corpus sobre el que se asienta la investigación se describen en $\S 4$. Por su parte, $\S 5$ contiene la exposición de los resultados más relevantes del análisis de regresión logística de efectos mixtos llevado a cabo, y cuyas implicaciones más destacadas se sintetizan en la sección final.

\section{CRONOLOGÍA Y DISTRIBUCIÓN DE LA VARIABLE LINGÜÍSTICA}

El adverbio así deriva del latín sīc, y de ahí su presencia en todas las lenguas romances (portugués: assim, catalán axí, occitano aissi, francés ainsi; italiano così, sardo gasi, rumano aşa, español: asî) (Corominas y Pascual, 1980-1991: 
s.v. asi). Ahora bien, en la mayoría de estas lenguas, las formas vernáculas han convivido con otras variantes morfológicas a lo largo de la historia. En el caso del español, así ocurre con formas como sí, ansí, asina y asina. Ello explica, como recuerda Rodríguez Molina (2015: 1049), las dificultades etimológicas que han encontrado los lingüistas para dar cuenta del origen de tales adverbios. Así, para el caso de ansí, una de las variantes analizadas en este trabajo, se han propuesto diversas hipótesis, sin que hasta la fecha ninguna de ellas haya podido ser considerada como irrefutable (véase un resumen de estas en Rodríguez Molina, 2015: 1054-1055).

De las variantes señaladas, en el corpus manejado en esta investigación tan solo hemos encontrado un número representativo de dos de ellas: así y $a n s i^{4}$. Por el contrario, apenas hallamos cinco ejemplos del resto (tres de asina y dos de ansina), como los que se reproducen a continuación ${ }^{5}$ :

(3) Y asina os digo que de ninguna manera bengais como digo, si no fuere con algun pasajero pagandolo (Documentos lingüísticos de la Nueva España, 1577).

(4) ....y todo esto no lo tengo en nada perdello anques mucho atento aguardalle en este puerto y ansina la ruego $\mathrm{q}$ sin inpedimiento ninguno se uenga (Cartas de particulares en Indias del siglo XVI, 1583)

Históricamente, se considera si como la variante más antigua, si bien habría desaparecido ya en el siglo XIII (Menéndez Pidal 1976: § 771), de ahí que no advirtamos ningún ejemplo en el corpus. A esta le habría seguido así -en sus diferentes variantes fonéticas y gráficas-, para la que se han propuesto diversos orígenes, como la derivación desde el latín AD SIC (Menéndez Pidal 1976) o la formación analógica a partir de otros adverbios que presentan también la $a$ inicial (Alonso 1930; Corominas y Pascual 1980-1991). Estos últimos autores consideran que ansí surge ya en el siglo XIII. Sin embargo, un expurgo documental reciente sobre textos originales o copias cercanas al momento de la escritura muestra que la forma asi (en particular, la variante fonética assi) es la única documentada antes de mediados del siglo XIV, además de gozar de una amplia difusión geográfica por toda la península (Rodríguez Molina 2015). Por el contrario, la primera ocurrencia de ansí

\footnotetext{
Agrupamos dentro de cada una de estas formas las diferentes variantes fonéticas y gráficas que aparecen en los textos. Por ejemplo, del adverbio asi encontramos ejemplos de: asi, assi, así, assj, asy. Por su parte, ansi está representado también por diversas formas alternativas: ansi, ansí, ansj, ansy.

5 Como señala Rodríguez Molina (2015: 1059), tampoco hay ocurrencias de estas dos formas en los textos del corpus CODEA fechados entre 1200 y 1600.
} 
en ese corpus debe esperar hasta 1368, a la que se añade una veintena más en el largo periodo comprendido entre esa fecha y 1500.

Desde un punto de vista dialectal, se ha advertido que ansi fue de raigambre centro-peninsular, en un área que abarcó desde el norte de Castilla y León hasta Extremadura y el noroeste de Andalucía. A los datos manejados por Rodríguez Molina (2015) sobre textos medievales y del primer español clásico, se unen los estudiados por del Barrio (2017: 254) sobre documentación de CODEA entre 1580 y 1620 . Para este autor, el apogeo de ansí durante el siglo XVI puede ponerse en relación con la llegada de importantes contingentes de población inmigrante provenientes de las regiones castellanas y leonesas a Madrid, una vez convertida esta en capital del reino a partir de 1561. Al mismo tiempo, esta distribución geolectal permitiría explicar su pervivencia hoy -aunque ya mucho más debilitada-en las hablas del oeste peninsular, además de en el judeoespañol y en algunas hablas hispanoamericanas (Alonso 1930; Corominas y Pascual 1980-1991; Cuervo 1886/1998; Rodríguez Molina 2015). Aun así, la información disponible es demasiado fragmentaria y resulta claramente insuficiente, sin que exista hasta la fecha un estudio de conjunto que la sistematice por completo.

Esta misma insuficiencia bibliográfica se aprecia en el plano diastrático. Así, en la última edición de la Gramática de la RAE/ASALE (2009: 1325) se censuran todas las formas alternativas a así, que se interpretan como propias del español de otras épocas, así como de algunas variedades contemporáneas del español popular y rural, aunque sin ofrecer más detalles. En esto, la Real Academia sigue todavía un criterio similar al instaurado desde su creación en el siglo XVIII, y que sistemáticamente ha venido considerando estas variantes como vulgares, rurales o dialectales, además de anticuadas. Como recuerda Rodríguez Molina (2015: 1051), la información sociolingüística en las monografías dialectales disponibles tampoco es muy útil para resolver esta cuestión, ya que en ellas no se indica si las formas alternativas a así son de uso general en sus respectivas comunidades de habla o, por el contrario, se localizan en ciertos sectores sociales o idiolectales. Y si las cosas son así en relación con el español contemporáneo, el panorama es todavía más precario si nos referimos a épocas pasadas.

En el caso del español clásico, no faltan, sin embargo, algunos testimonios que permiten hacernos una idea acerca de ciertas actitudes lingüísticas que esta variación pudo despertar en la época (al menos entre ciertas élites), si bien estos no ofrecen una imagen uniforme. Así, en el siglo XVI, coincidiendo con el apogeo de ansí, Juan de Valdés incluye esta voz entre esos "bordones" que la gente repite "tantas vezes que os vienen en fastidio grandíssimo [y que] tras cada palabra os dan con él en los ojos" (del Corral 2013: 3641). 
Sea como sea, Valdés interpreta que en esa "palabrilla" "está mejor la $s$ que la $n$ " (Lope Blanch 1969: 101). Aun así, el propio humanista español utiliza la forma en un $20 \%$ de las ocasiones en que aparece el adverbio en su Diálogo de las cosas acaecidas en Roma (c. 1529), proporciones similares a las detectadas en la Floresta española (1574) por Melchor de Santa Cruz (Rodríguez Molina 2015: 1058). Sin embargo, las cifras se disparan en otros textos de la época, como en la Gramática de Villalón (1558), donde se emplea sistemáticamente en todo el texto. E incluso, ya en pleno siglo XVII, Gonzalo Correas (1909 [1627]), poco amigo de rusticidades, mostraba una clara predilección por esta forma:

Ansi afirma i dize el modo como algo se hizo, ó se hará, i ia le quitan la $n$ mui de ordinario, i dizen asi, i escriben assi con dos eses contra toda buena rrazon $[\ldots]$ Por mexor tuviera rretener la $n$ ansi $[\ldots$ ] i por parecerme esto mexor le uso en todo este libro ansi por huir del abusso de escriuirle con dos ss $[\ldots]$

En una contribución reciente a la que nos referíamos más arriba, del Barrio (2017) comprueba que, pese a la predilección por la forma así en los textos más formales de la Cancillería, la variante ansi aparece con cierta frecuencia en los textos expurgados del corpus CODEA entre 1581 y 1620 (36\%), pero sobre todo en los documentos judiciales, donde llega a rebasar ampliamente a la primera (84\%). Todo ello vendría a demostrar que ansí, marcada como dialectal y diafásicamente desde el siglo XVIII (Medina Morales 2005: 253; Rodríguez Molina 2015: 1051) tenía, sin embargo, una amplia presencia en los contextos formales y públicos de los Siglos de Oro. Ahora bien, los resultados de este estudio muestran al mismo tiempo un patrón curvilíneo por el cual las proporciones de ansí en los dos extremos de la escala de formalidad (textos cancillerescos y documentos particulares) se asemejan entre sí, y difieren notablemente de los textos judiciales ya mencionados. Asimismo, desconocemos si tales diferencias son estadísticamente significativas, y si a ello puede contribuir la escasa muestra global disponible, los desequilibrios muestrales entre los diferentes contextos (judicial: $N=25$; Particulares: $N=$ 61) o la concentración de algunos de estos usos en ciertos idiolectos.

Así las cosas, dadas las aparentes contradicciones que sobre el prestigio sociolingüístico de las formas así y ansí encontramos en los Siglos de Oro, analizamos esta cuestión mediante el estudio de un corpus mucho más amplio, compuesto por textos cercanos a la inmediatez comunicativa, aunque con diferencias de registro importantes en su interior, y a cargo de individuos repartidos por todo el espectro social. De la codificación de estos factores, así como otros de naturaleza lingüística, se ocupa el siguiente apartado. 


\section{CONTEXTOS DE USO Y CODIFICACIÓN}

\subsection{USOS LINGÜÍSTICOS DE LA VARIABLE EN EL CORPUS}

Una de los rasgos más destacados de así es que, frente a otros adverbios de manera, es el único capaz de expresar deixis (Bosque 1989:199-205; RAEASALE 2009: §30.1-30.2), lo que explica que, en la tradición gramatical se haya considerado como un adverbio demostrativo o identificativo. Asimismo, se trata de una palabra en la que se combinan a partes iguales un componente léxico y otro gramatical, lo que convierte la unidad en una proforma, capaz de sustituir a otras en el discurso. Además, es uno de los adverbios demostrativos que cuenta con una evolución diacrónica más compleja, ya que el significado básico de "manera" ha convivido a lo largo de la historia con otros de carácter gramatical y discursivo, como la cuantificación, la subordinación y la marcación discursiva. A juicio de Rodríguez Molina (2014a: 914), el significado deíctico exofórico habría sido el más básico y antiguo, a partir de él se derivarían los usos endofóricos, y, desde estos últimos -en especial los de carácter anafórico- aquellos que han convertido al adverbio en un conector consecutivo. Con todo, advierte el autor, todos estos empleos se observaban ya en latín, por lo que el español antiguo no habría hecho más que continuar las tendencias ya existentes en la lengua madre.

Entre los usos que se han señalado en la bibliografía, en el corpus encontramos los siguientes.

\section{Adverbio de manera}

Como se ha señalado, este valor deíctico es, probablemente, el sentido original, y de él encontramos ejemplos tanto de naturaleza exofórica como endofórica. En todo caso, en el primer caso, la identificación de la referencia extralingüística no siempre es fácil de delimitar, especialmente en textos escritos para los que el lector no dispone del marco comunicativo completo. Así ocurre con $(5)^{6}$, donde el autor de una carta a su familia en España indica la manera en que debe realizarse cierta acción destinada a

\footnotetext{
6 Salvo excepciones, y por motivos de espacio y oportunidad, en lo que sigue transcribimos únicamente ejemplos de la forma ansí, lo que no impide que, conforme al principio de responsabilidad ante los datos (Labov 1972), esencial en cualquier trabajo sociolingüístico, en todos los casos hayamos recogido y analizado también las muestras de la variante alternativa, esto es, así.
} 
propiciar la reunificación familiar en América. Por el contrario, en los dos ejemplos siguientes, el remitente apunta mediante el adverbio a una entidad lingüística mencionada en el texto, ya sea con anterioridad, como muestra el uso anafórico de (6), ya con posterioridad, y de ahí empleos catafóricos como los de (7). En ambos casos puede tratarse tanto de palabras aisladas como de fragmentos enteros, pero también de enunciados implícitos que se sobreentienden contextualmente.

(5) ... yo lo tendre avisado que lo aga ansi (Cartas de particulares en Indias del siglo XVI, 1568)

(6) ... sy no es quando enbyo algo nunca jamas escrebys ny os acordays de my y en berdad q ella tyene razon yo ansy se lo dygo (Cartas de particulares en Indias del siglo XVI, 1569)

(7) ... esto paso ansi abajarô a santyago rrobarô lo q Vra exc ${ }^{\mathrm{a}}$ abra sabydo y fueronse azia copiapo despacharô al galet los de santyago (Documentos para la historia lingüística de Hispanoamérica, 1579)

\section{Marcador discursivo}

Los frecuentes usos anafóricos de así justifican la posibilidad de reinterpretar la circunstancia original como una consecuencia y, por consiguiente, su gramaticalización como un marcador discursivo perteneciente a la esfera de los conectores consecutivos (Cuervo 1886-1998:s.v. así; Martín Zorraquino y Portolés Lázaro 1999; Santos Río 2003:201-209; Seco, Andrés y Ramos 1999:s.v. así; del Corral 2013: 3644; Rodríguez Molina 2014b: 912-913). Presente ya en el español medieval, estos usos son muy frecuentes en nuestro corpus, lo mismo que en otros de carácter más formal, como demuestra el estudio de del Corral (2013) sobre cartas oficiales ecuatorianas de la misma época. Es posible que el carácter conversacional implícito en la correspondencia (Fernández Alcaide 2009) ${ }^{7}$, pueda explicar la especial recurrencia de estos usos en las cartas.

Las variantes de sentido que se engloban bajo el paraguas de esta categoría son diversas, y van desde las relaciones de "explicación-deducción" y "causa-efecto", habituales entre las oraciones consecutivas (Álvarez 1999: 3793), a otras de carácter metadiscursivo, como la ejemplificación, la mera ilación discursiva "de continuidad" o el cambio de tema (Cano

\footnotetext{
7 De hecho, para esta autora la aparición de estos adverbios demostrativos (incluidos también los de lugar, aquí, allí, etc.) puede ser un indicio de inmediatez comunicativa, dado que implican directamente a los interlocutores.
} 
Aguilar 2007: 34-35) ${ }^{8}$. Según este último autor, para que así funcione como conector supraoracional en el siglo XVI "parece obligado que se encuentre reforzado por y" (Cano Aguilar 2007: 35) . Los ejemplos siguientes son representativos de este contexto. Así (9), ilustra una relación de "causa" ("no a querido tomar mi consejo en cosa que / le ai[a] dicho'), cuyo "efecto" (' $y$ ansí no me doi nada por él'), el remitente explica a su destinatario. Por su parte, (10) muestra el valor ejemplificador del adverbio:

(9) Yo [e] echo lo que e podido por él; no a querido tomar mi consejo en cosa que le ai[a] dicho, $y$ ansí no me doi nada por él (Cartas de emigrados andaluces, 1582)

(10) Ningún nabío sale de esta tierra que vaya sin mis cartas y ansí, por el mes de otubre pasado de 65 partió de aquí vna carauela en la qual escrebí a vuestra merced... (Cartas desde la otra orilla, 1566)

En la actualidad, ese valor conectivo es perfectamente posible también sin la presencia de la conjunción (Martín Zorraquino y Portolés Lázaro 1999). $\mathrm{Y}$, aunque mucho menos frecuente que el anterior, también encontramos algunas ocurrencias de este contexto entre los materiales de nuestro corpus, como el que ilustra el fragmento siguiente:

(11) y se avia de sacar por gran pleyto y a riesgo de mi persona ansi señora mia si os determinardes de venir alla [en]bie mi poder por dos vías... (Cartas de particulares en Indias del siglo XVI, 1574)

Otra vía importante para la codificación de esta clase de sentidos es, finalmente, el empleo de la locución conjuntiva así que, con la se expone normalmente la consecuencia derivada de una situación enunciada previamente (Cano Aguilar 2007: 35). El siguiente es un ejemplo representativo:

8 Sin embargo, apenas encontramos un ejemplo con valor recapitulativo, como el que encierra la locución conjuntiva así pues, esta vez con la forma más frecuente, y sin correlato, pues, con ansí:

(8) ... el sera muy bien tratado como le pertenesce para ello le proveeran bien en sevilla en mi nonbre y asi pues que hasta aqui hable con quien primero era obligado... (Cartas de particulares en Indias del siglo XVI, 1580)

Estos resultados coinciden con los datos manejados por Cano Aguilar (2007: 37), quien advierte que son muy pocos los ejemplos de esta combinación en el siglo XVI. Y lo mismo parece suceder en el XVII, a juzgar por los datos del presente estudio.

9 Ocasionalmente, $e$ también (Keniston 1937: 667). 
(12) ... y a mí me pareçía fue el mandar yo más de lo quellos mandaban pues no me aprovechará nada; ansí que, señor, pagado lo dicho no quedaron más dineros... (Cartas desde la otra orilla, 1552)

\section{Locuciones adverbiales y conjuntivas}

Junto a los valores deícticos y discursivos ya reseñados, el adverbio así aparece también en una serie de locuciones adverbiales y conjuntivas, en combinación con otros elementos. Así ocurre, por ejemplo, con el adjetivo mismo con valor aditivo, cuya presencia junto a ansí se mantiene hasta bien entrado el siglo XVII (en el mismo sentido, véase Sánchez 1997: 340):

(13) El nos dio en rrentas en sus rreinos todo lo que se montaua en el prestido ansi mismo hizo muchas merçedes a todos los conquistadores (La memoria de Juan Ruiz de Arce, 1543)

Lo mismo sucede con otras locuciones y estructuras correlativas con como, que dan lugar a sentidos diferentes, como la comparación (14), el valor temporal (15) o la conexión copulativa (16):

(14)... debe valer a Luis de Mercado, residente en la corte de S.M. que esta absente, bien ansi como si estuviera presente... (Cartas privadas de Hernando Gorjón, 1545)

(15) ... si mi hermano agustin lopes le diere gusto venir y vmd lo dejare qs lo q deseamos antes q salga de la veracruz ansi como llegue la flota nos escriva (Cartas de particulares en Indias del siglo XVI, 1574)

(16) ... el qual tengo en lugar de hermano y e tenido en esta Nueva España desdel día que nos partimos de esa villa de Madrigal hasta hoy, día de la fecha, e ansimesmo nos tememos avnquél esté allá, ansí en voluntad como en obras (Cartas desde la otra orilla, 1539)

\section{Otros valores}

En el corpus encontramos también algunos usos más esporádicos de otras funciones, como el valor concesivo en combinaciones con el verbo de la subordinada en subjuntivo (17), el empleo interjectivo del adverbio (18) o su papel como cuantificador en estructuras con la preposición de (19) (Octavio de Toledo y Huerta y Sánchez López 2009: § 9.2.7.2; Rodríguez Molina 2014a: 911, 915).

(17) Mira, conpadre, ¿qué habla éste que me llamó marrano?, que ansy me llamara converso non me diera nada, porque converso quiere decir honbre convertido (Conversaciones estrechamente vigiladas, 1491) 
(18) ... y fue que como benia tanta gente en el nauio beniamos tan estrechos, que ansi me de dios el çielo y me dexe oyr buena[s?] nueuas de toda su casa de vm (Cartas de particulares en Indias del siglo XVI, 1587)

(19) ... que yo cierto tenía entendido que ya no tenía hijos según la muncha perdi[ci]ón que estos años avido ansí de guerra y rrefriagas (Die Korrespondenz spanischer Emigranten aus Amerika, 1590)

Por último, hemos advertido también algunos empleos aislados del adverbio como modificador de una categoría nominal, si bien en este caso las escasas ocurrencias $(N=2)$ se limitan a la forma así. Esta es una de ellas:

(20) Y siendo cierto que no te han de dejar sin algún castigo, de ir a servir a Orán o cosa así, no tendría yo mal día si ahora me dijesen ha de parar en esto (Carta del duque de Osera a su hermano, 1656)

Como recuerda Rodríguez Molina (2014b), algunos de estos empleos más esporádicos suponen una novedad romance con respecto al latín y de hecho, no se generalizarían hasta mucho después en la historia de la lengua (el caso de la modificación nominal o el valor cuantificador).

\subsection{CODIFICACIÓN}

Para poner a prueba la posible equivalencia semántica y sintáctica de las dos variantes consideradas, en el estudio cuantitativo codificamos la variable de acuerdo con diversos predictores lingüísticos.

\subsubsection{Sentido}

Los usos reseñados en el apartado anterior pueden agruparse en cuatro grupos, en función del valor semántico que el adverbio aporta al enunciado. Con independencia de cuáles sean las expresiones concretas utilizadas en cada caso, estas sirven para la expresión de sentidos aditivos, consecutivos y modales. Finalmente, en la categoría de Otros incluimos los valores que hemos advertido como más esporádicos. Los ejemplos a continuación son representativos de cada uno de ellos.

\section{Adición}

(21)... vuestra señoria nos enbie los despachos E se haga de manera que los vezinos desta ysla seamos algo aprovechados. Ansi mismo le 
suplicamos a vuestra señoria nos haga merçed de aver de su magestad algunas liçençias para traer a esta ysla negros (Textos del Caribe, 1556)

(22) ... me dexo por eredero vnibersal de todos sus bienes ansi los que tine en yndias como en españa abidos por erençia de sus padres (Cartas de particulares en Indias del siglo XVI, 1587)

\section{Consecuencia}

(23)... me podrán hazer algún daño de manera que no pudiese acudir a lo necesario tan libremente. Ansí que por me hazer merced e por lo que a v[uest]ros hijos conviene báis a Madrid (Die private Korrespondenz spanischer Emigranten aus Amerika, 1572)

(24) .... hasta que V.Sa tenga memoria de mí, acatando lo mucho que el Vicechanciller, mi señor, le desseava servir. Y, ansí, suplico a V.Sa. que, haviendo opportunidad me mande reçebir en su servicio (Ocho cartas de placer de palacio y una de disparates de Corte, 1552)

\section{Manera}

(25) ... y pora mí son estas cossas tan odiosas que aun en cartas no me atreviera a dar Razón de nada y quédese esto ansí Porque el tiempo dará a entender quan necesario es preuenir los casos... (Cartas de mercaderes, 1575)

Otros

(26) .... y estauan muchos yndios alrredor de nosotros mirando entre vnas junqueras que auia muy largas y muchas. Ansi como arremetio vn cauallo huyeron treinta o quarenta yndios (Memoria de Juan de Arce, 1543)

(27) .... se entiende que no puede ser justa, proporcionada ni equivalente, sino que ansí como el que compra joyel de oro lleno de piedras preciosas y esmaltes por solo el peso, no satisface así el que compra vasallos, villas y fortalezas de las iglesias por el valor de la poca renta: está claro que lo lleva por solo el peso y deja de pagar las piedras y esmaltes de la honra (Memoria manuscrita, 1574)

\subsubsection{Categoría}

De lo advertido más arriba, se desprende que tanto ansí como así funcionan unas veces como adverbio, como ilustra el ejemplo de (28), mientras que otras lo hacen como representantes de otras categorías, como la conjuntiva en (29): 
(28) ... mandándole que el día siguiente por la mañana volviese y trujese consigo a su mujer y al niño y algunos de los nombres que habían sido curados. Hísolo ansí (Epistolario entre Luisa de Carvajal y el conde de Gondomar, 1612)

(29) Estube en el camino y fi persuadido de munchos amigos y aconsejado que no era cosa que me conbenia por tener tan buen comodo como al presente tengo ansi en ganar de comer como en buen abio para que os bengays sin yr yo alla (Los movimientos migratorios entre Castilla e Hispanoamérica durante el reinado de Felipe III, 1589)

\subsubsection{Cotexto}

Una revisión inicial de los datos llevó a percatarnos de que la presencia de la conjunción $y$ junto al adverbio era una construcción muy habitual en el corpus, hasta el punto de representar el $53 \%$ de todos los ejemplos $(N=1164)$. Este hecho, que podría ser un indicador de inmediatez comunicativa -piénsese en la frecuencia con que aparece también en el español conversacional contemporáneo- ${ }^{10}$ afecta a los usos de así como marcador discursivo, como el representado en (30), pero no faltan otros valores en los que el adverbio va también precedido por la conjunción copulativa. Así ocurre, por ejemplo, en (31), donde ansí posee un valor deíctico, no conectivo.

(30) ... questa en su casa con el qual estuue parlando hasta que bino y ansi como bino le dixo qel dho Simon quien yo hera (Cartas de particulares en Indias del siglo XVI, 1587)

(31) ... y esos señores las pagasen y las cartas de venta rreçen a la dicha su hija, la menor que está por cassar, para su dote y cassamiento. y ansi se haga; y en el entretanto que se casse... (Cartas desde la otra orilla, 1570)

En consecuencia, deseamos comprobar si este hecho sintagmático puede tener alguna relevancia explicativa frente al resto de ocurrencias de la variable, en las que el adverbio aparece sin el auxilio de la conjunción.

10 Agradecemos a uno de los evaluadores anónimos del artículo esta observación, que compartimos. 


\subsubsection{Posición}

Salvo en los usos deícticos, la posición del adverbio es fija con respecto al verbo de la oración que introduce. Sin embargo, cuando conserva su valor original, esto es, cuando funciona como un adverbio de modo, puede aparecer tanto en posición antepuesta como pospuesta. Los dos ejemplos siguientes ilustran estas dos posibilidades con el mismo verbo ser, conjugado en ambos casos en futuro:

(32) Esta sera para hacer sauer a vmd como estoi bueno de salud esperando en dios que asi sera de bos y de todos los amygos y amygas (Cartas de particulares en Indias del siglo XVI, 1583)

(33) ... en serviçio de nro senor que yo espero en su divina majestad que sera ansi porque ansi se lo ruego yo muy encareçidame todos los dias (Cartas de particulares en Indias del siglo XVI, 1591)

\subsubsection{Función}

También reservado a los usos deícticos del adverbio, con este predictor deseamos someter a prueba la hipótesis acerca de la existencia de posibles diferencias cuando este desempeña una función argumental, como la de atributo o predicativo (34), frente a la de adjunto o complemento circunstancial de modo en casos como los de (35):

(34) ... que asimismo he consultado esto con hombres muy doctos de çiençia y conciençia, que si no fuera assí no lo escriuiera (Cartas desde la otra orilla, 1640)

(35) Los rreligiosos de este vuestro conbento de sancto Domingo pedimos $\mathrm{P}$ a vuestro visorrey tubiese por bien que se estubiesen entre nosotros para industriarlos en las cosas de nuestra sancta fee catholica, y tambien para que se aficionasen a los rreligiosos. Lo qual ansi se hizo (Documentos lingüísticos de la Nueva España, 1563).

\subsection{FACTORES EXTRALINGÜÍSTICOS}

Como apuntábamos más arriba $(\S 2)$, escasa es la información segura acerca de la distribución sociolingüística de la variable lingüística en los Siglos de Oro. Así, las actitudes hacia el uso del adverbio ansí entre algunos usuarios de la época no siempre eran coincidentes, de tal manera que, junto a opiniones adversas como la de Valdés, encontramos también una defensa entusiasta entre algunos gramáticos (Correas), e incluso usos sistemáticos de 
la variante por parte de otros (Villalón). Por otro lado, los escasos estudios sobre la cuestión se han centrado en el plano dialectal, pero no tanto en el socioestilístico, quizá por la ausencia hasta tiempos recientes de corpus suficientemente amplios y representativos de la época. $Y$ los pocos existentes hasta la fecha presentan un panorama poco definido. Así, en el trabajo de Rodríguez Molina (2015: 1062) sobre textos literarios y humanísticos del siglo XVI, encontramos resultados muy diferentes entre unos escritores y otros. Junto a algunos que hacen un uso preferente (Lucas Fernández) y hasta categórico del adverbio (el ya mencionado Villalón), encontramos otros mucho más reacios (Bartolomé de las Casas, Valdés, Santacruz). Por su parte, del Barrio (2017), en el mencionado estudio sobre textos del corpus CODEA entre 1580 y 1620 , periodo de máximo apogeo del adverbio ansí, comprueba la existencia de empleos muy elevados en textos judiciales, pero muy inferiores en otras tradiciones formales, como los escritos de la Cancillería o los textos eclesiásticos. Con todo, lo más sorprendente es que estos últimos difieren poco de los encontrados entre los documentos particulares, que se sitúan en el otro extremo del eje de formalidad.

Todo lo anterior justifica el interés que suscita en este estudio el análisis del condicionamiento extralingüístico de este fenómeno de variación, para lo que contamos con un corpus amplio y representativo de todo el espectro social. Con este fin codificamos las ocurrencias de la variable de acuerdo con los siguientes predictores:

- Sexo: hombres / mujeres.

- Estatus social: a partir de una clasificación tripartita, adaptada a la estructura social de los Siglos de Oro, (Fernández Álvarez, 2004), distinguimos entre:

- Estrato alto: miembros de la realeza, la nobleza (duques, condes, marqueses...) y el alto clero (obispos, arzobispos, cardenales, superiores de órdenes monásticas y conventos, jueces de la Inquisición, etc.), así como representantes de la élite cultural de la época (escritores, humanistas, gramáticos, etc.).

- Estrato medio: compuesto por cargos intermedios del clero y la nobleza baja, representantes de una creciente burguesía urbana (escribanos, licenciados, doctores, mercaderes, funcionarios, etc.), oficiales del ejército, etc.

- Estrato bajo: en él se sitúan los representantes de diversas profesiones manuales, como campesinos, panaderos, carpinteros, torneros, toneleros, albañiles, herreros, soldados, y un largo etcétera, así como pequeños 
propietarios que intentaron hacer fortuna en las Américas, muchas veces sin conseguirlo y añorando cada día más a sus seres queridos.

- Tenor: este factor está concebido a partir del tipo de relación y la temática de los documentos que integran el corpus. A partir de ambos parámetros dividimos el continuum estilístico en tres grados. En un extremo se sitúan los textos que consideramos más cercanos y personales, en los que se incluyen las cartas entre individuos a los que unen estrechos lazos íntimos o familiares. En el polo opuesto, ubicamos los textos más distantes, como la correspondencia entre individuos claramente alejados en el eje del poder y la solidaridad (cartas entre desconocidos, entre inferior y superior (o viceversa), etc.). Finalmente, agrupamos en un nivel intermedio el resto de textos, que no encajan canónicamente en ninguno de los dos polos mencionados. En este se incluyen las cartas escritas entre personas conocidas, pero relacionadas por vínculos menos estrechos que las más personales (amigos no íntimos, familiares lejanos, etc.), pero incluso también las intercambiadas entre individuos más cercanos, cuyos textos aparecen teñidos, sin embargo, por una evidente mayor distancia comunicativa, bien visible, por ejemplo, en encabezamientos y despedidas, así como en el tono general de las epístolas.

Compárese, por ejemplo, el tenor de estas dos cartas, dirigidas en ambos casos a una madre, y cuyas secuencias periféricas transcribimos parcialmente a continuación (Fernández Alcaide 2009: 747). En la primera, Andrea López de Vargas encabeza su escrito con un sentido "señora madre de mi corazón", y continúa relatando, en un tono muy afectivo, la emoción "infinita" que produjo en ella la lectura de una carta anterior enviada desde Cádiz por su progenitora, además de otras vicisitudes personales que habían tenido lugar en el tiempo en que no habían sabido nada una de la otra, y que, por razones de espacio, no podemos reproducir aquí.

$\mathrm{s}^{\mathrm{a}}$ madre de mi coracon

la de vmd resebi q fue la $\mathrm{q}$ me traxo $\mathrm{p}^{\mathrm{o}}$ de morales y con ella resebi tanto contento q querello dezir aqui seria ynfinito y lo resebi muy grāde en $\mathrm{q} \mathrm{p}^{\mathrm{o}}$ de morales me dixo vido a vmd y estuvo hablando cō vmd y mis hermanas q fue cosa q me dio el contento q solo dios lo sabe y es testigo... [...]

señora madre

besa las manos a vmd

su hija

andrea lopez de Vargas (Cartas de particulares en Indias del siglo XVI, 1577) 
Por el contrario, en (37), un capellán residente en México envía una misiva a su madre, que encabeza con un protocolario "Ilustre señora", y despide con una fórmula no menos convencional, en la que, además, se subraya no tanto la figura filial, sino la dignidad religiosa ostentada. Y todo ello, además, con el fin instrumental de recabar noticias acerca "unas haciendas tan buenas" que, al parecer, se habrían perdido tras la muerte de unos familiares comunes:

ille señora

muchos dias ha q no he visto carta de vm aunque por las de mi señora doña teresa nra hermana he savido de la salud de vm y de sus hijos y muerte de los señores rodrigo de la fuente y alonso xuarez q lo he sentido ternisimamte plega a nro sor de darles el çielo y a esas señoras paçiençia para tantos travajos como le quedan q estoy maravillado que unas haziendas tan buenas como las que tenian se ayan perdido pues quando yo pase en estas provinçias sola la herençia que rodrigo de la fuente huvo de doña teresa nra prima valio mas de quarenta mill dus aunque mas me maravillo de la de alonso xuarez siendo vinculada se aya deshecho, dios lo remedie todo.

$[\ldots]$

çeso en esta rogando a $\mathrm{n} \mathrm{s}^{\text {or }}$ guarde a vm como yo deseo de potosi y de 10 septiembre a $\operatorname{pri}^{\circ}$ de 1574 años

b $1 \mathrm{~m} \mathrm{~d} \mathrm{vm}$

su capellan (Cartas de particulares en Indias del siglo XVI, 1574)

- Contexto migratorio: este factor nos permite separar los textos que se escribieron desde España y los redactados desde América, generalmente en situaciones de intenso contacto interdialectal, y más proclives, por tanto, a desviaciones con respecto a la norma de la metrópolis. En este sentido, deseamos probar la hipótesis acerca de la mayor fortuna de ansí en el continente americano, que alguna vez se ha propuesto (ver $\S 2$ ).

- Procedencia dialectal: dividido a su vez en dos predictores, basados en sendas divisiones habituales en la lingüística diacrónica del español:

- Comunidades norteñas / centro-meridionales

- Comunidades centro-occidentales / orientales

Sin embargo, a diferencia de los anteriores, en ambos casos nos encontramos con algunas lagunas en el corpus, ya que desconocemos el origen concreto de varios escritores. Por ello, para el estudio de la procedencia dialectal llevaremos a cabo un reanálisis, en el que se incluirán tan solo las ocurrencias 
de la variable cuyo origen geolectal es conocido, obviando aquellas en las que ello no es así (ver más detalles en $\S 5.3$ ).

El cuadro de factores extralingüísticos se cierra con un factor continuo, el año en que se escribieron los textos, lo que nos permitirá evaluar la existencia (o no) de cambios significativos durante el periodo estudiado. Finalmente, todos los análisis pasan por el filtro del escritor, un factor aleatorio que nos ayuda a calibrar con más precisión el poder explicativo de cada uno de los predictores reseñados.

\section{CORPUS Y METODOLOGÍA}

Como hemos indicado más arriba, el corpus del presente estudio está compuesto íntegramente por textos cercanos al polo de la inmediatez comunicativa, en los que, pese a una transmisión escrita, la concepción oralizante ocupa un lugar destacado en su caracterización (Oesterreicher 2004). Entre estos sobresalen por su maginitud los documentos epistolares, especialmente las cartas privadas, que en los últimos años se han convertido en un fértil instrumento para el estudio de la lengua vernácula en épocas pretéritas (Elspass 2012; Schneider 2013). A estos se añaden, en menor medida, otras manifestaciones escritas cercanas al polo de la inmediatez, como diarios, memorias, libros de cuentas, declaraciones ante tribunales de justicia, etc.

Dada la importancia que la edición de los materiales escritos tiene para el análisis de un fenómeno de variación como el presente, en la selección del corpus hemos considerado tan solo aquellas obras en las que, o bien el texto se ha preparado con criterios estrictamente filológicos o, aunque no haya sido así, sus editores reconocen no haber modernizado nada que vaya más allá de aspectos tales como la acentuación o la puntuación, o cuestiones ortográficas periféricas para nuestros actuales intereses (uso de mayúsculas, desarrollo de abreviaturas, etc.), con el fin de facilitar la lectura (ver la relación de obras que integran el corpus en el Anexo). Las ediciones trabajan en su mayoría con textos originales, aunque hay también una pequeña representación de copias cercanas al momento de la escritura.

Como se puede observar en la Tabla 1, el corpus supera el millón y medio de registros, con una leve mayor representación del siglo XVI que del XVII. Sin embargo, ese desequilibrio es considerablemente mayor en el número de escritores representados, lo que, al menos en parte, justifica unas cifras de 
la variable muy irregulares en cada periodo, con ocurrencias notablemente mayores en el siglo XVI que en la centuria siguiente (ver $\S 5.1)^{11}$.

\begin{tabular}{|l|c|c|}
\hline & $\mathbf{N}^{\mathbf{0}}$ palabras & $\mathbf{N}^{\mathbf{0}}$ escritores \\
\hline Siglo XVI & 876.906 & 805 \\
\hline Siglo XVII & 681.329 & 210 \\
\hline TOTAL & 1.558 .235 & 1.015 \\
\hline
\end{tabular}

Tabla 1: Dimensiones del corpus por siglos

Aunque el conjunto de informantes supera el millar, tan solo hemos encontrado alguna muestra de la variable lingüística en menos de la mitad $(N=451)$. En la mayoría de los casos, estas muestras tienen una representación limitada (entre una y tres ocurrencias). Sin embargo, en los epistolarios y escritos autobiográficos más extensos a cargo de un solo escritor, los ejemplos de la variable son, por lógica, más numerosas. Ello hace indispensable el empleo de un modelo estadístico en el que este potencial sesgo idiolectal pueda ser corregido. Para ello, acudimos al programa Rbrul (Johnson 2009), el cual permite la realización de un análisis de regresión logística de efectos mixtos y, por tanto, la consideración de factores de diferente tipo y no solo fijos o categóricos, como sucedía en las aplicaciones estadísticas clásicas de la sociolingüística variacionista (Varbrul, Goldvarb). De este modo, el tratamiento del tiempo como lo que es, un predictor continuo, nos permitirá evaluar con precisión la relevancia del eje temporal en el fenómeno de variación. Asimismo, el concurso de factores aleatorios, como la identidad de cada uno de los escritores, hace posible un estudio más afinado de la robustez alcanzada por los demás factores, tanto lingüísticos como extralingüísticos. No en vano, el modelo mixto de regresión tan solo otorga significación a uno de estos predictores si su efecto es más fuerte que el ejercido por el factor aleatorio en cuestión (Johnson, 2009: 365).

Las magnitudes que arroja Rbrul abarcan no solo frecuencias absolutas y porcentajes, sino también la relación de predictores seleccionados como

11 En buena medida, ello obedece a la presencia entre los materiales del siglo XVI de la excelente edición de más de seiscientas cartas de indianos publicada por Fernández Alcaide (2009), Cartas de particulares en Indias del siglo XVI, que por sí sola alberga la correspondencia de más de quinientos escritores diferentes. Y en este inmenso banco de datos epistolar, la posibilidad de que una palabra con valores deícticos y discursivos tan frecuente como asi aparezca en el contenido de las cartas, es elevada. Desafortunadamente, no contamos con nada similar entre las ediciones del siglo XVII, al menos hasta donde llega nuestro conocimiento. 
significativos (y no significativos) para explicar de manera independiente la variación a la luz de la muestra disponible, así como las posibles interacciones entre estos. La significación estadística de los factores seleccionados se mide en pesos explicativos (valores P.), que oscilan entre las cifras extremas del 0 y el 1. Frente a estos valores, que revelan la ausencia de variación, los situados entre el 0.5 y la unidad se asocian a factores que condicionan favorablemente la variante de referencia, y que, como se recordará, en el presente estudio es la forma ansí. Por el contrario, los ubicados por debajo del 0.5 identifican a los condicionantes menos favorables, en una escala que se acentúa conforme más nos acercamos a 0 .

\section{RESULTADOS Y ANÁLISIS}

\subsection{RESULTADOS GENERALES Y EVOLUCIÓN}

De las 2206 ocurrencias de la variable lingüística de que consta la muestra definitiva, $936(42 \%)$ corresponden a la variante ansí en sus diferentes variantes fonéticas y gráficas (ver nota 4), mientras que las 1270 restantes (58\%) pertenecen a las diversas formas que se recogen de así. En consecuencia, aunque minoritaria en relación con la variante más antigua y común, estos resultados confirman la considerable vitalidad que ansí tuvo en los Siglos de Oro. Incluso los datos disponibles para el siglo XVI son superiores a los recogidos en algunos recuentos previos. Así, en una muestra de textos literarios de esa centuria expurgada por Rodríguez Molina (2015: 1061), este autor obtiene unas proporciones del $25 \%$, a considerable distancia de las recogidas en el siglo anterior (6\%), pero lejos también de las cifras manejadas en la presente investigación (42\%). Una diferencia, en definitiva, que revela cómo la suerte de una misma variable lingüística puede fluctuar significativamente en tradiciones discursivas diferentes ${ }^{12}$. El hecho de que el corpus utilizado en este trabajo esté más cercano a la oralidad que la lengua literaria hace pensar también que el uso de ansí en la lengua vernácula pudo

\footnotetext{
12 Así lo hemos comprobado, por ejemplo, en diversos estudios acerca de otras variables gramaticales en los Siglos de Oro, como las perífrasis deber (de) + infinitivo y haber de + infinitivo (Blas Arroyo et al. 2019), así como en fenómenos de variación que afectan a otros adverbios demostrativos, como los de lejanía (allílallá) (Blas Arroyo y González 2019).
} 
tener una distribución más amplia que la intuida hasta la fecha. Asimismo, posee implicaciones socioestilísticas interesantes, de las que nos ocuparemos con detalle más adelante.

Ahora bien, la difusión de ansí difiere considerablemente entre esta centuria y la siguiente. Aunque, como vimos más arriba (ver $§ 4$ ), el corpus muestra una distribución irregular, con muchas más ocurrencias de la variable en el siglo XVI $(N=1607)$ que en el XVII $(N=599)$, las diferencias son reveladoras y significativas estadísticamente (XVI: $49 \%$ vs. XVII: $24 \%$ ). Sin embargo, un análisis más detallado, como el que ofrece el Gráfico 1, en el que el eje temporal se divide en periodos de dos décadas, revela una clara distribución curvilínea y la existencia de varios momentos en la evolución del adverbio durante el español clásico. En él se puede observar, en efecto, cómo el verdadero apogeo de ansí tiene lugar en el periodo comprendido entre 1540 y 1600 , cuando llega a disputar incluso la supremacía a $a s i^{13}$. Esta fase exhibe un incremento muy notable con respecto a las décadas anteriores del siglo XVI, en las que la forma contaba ya con un índice de difusión importante (28\%) -superando así con creces las cifras de la centuria anterior- ${ }^{14}$, pero todavía a notable distancia de la otra variante. Eso significa que, en el plazo de apenas cuatro décadas, el adverbio ansí dobló prácticamente sus empleos, entrando así en una fase de cambio abrupto (Nevalainen y Raumolin-Brunberg 2003; Conde Silvestre 2007). Ahora bien, con la llegada del siglo XVII, la suerte del adverbio comenzó a cambiar. Todavía aguantaría en proporciones nada desdeñables durante las primeras dos décadas (40\%), pero su estrella comenzó a declinar progresivamente, con un descenso especialmente significativo a partir de 1640. Desde entonces, la variante empezó a decaer bruscamente, hasta desaparecer en el último periodo.

En resumen, la evolución de ansí en los Siglos de Oro responde al perfil de un cambio lingüístico en el que una variante vernácula avanza rápidamente durante un breve periodo de tiempo. Sin embargo, este proceso no solo no acaba de culminar, sino que se revierte con igual rapidez, hasta el punto de

13 En este sentido, nuestros datos difieren de los hallados por del Barrio (2017: 257) en textos de particulares extraídos del corpus CODEA entre 1580 y 1620 , coincidiendo con el momento de máximo esplendor de ansí. En ese estudio, la representación del adverbio no supera el $23 \%$ en el registro más cercano al contemplado en estas páginas, una cifra que contrasta notablemente con las obtenidas en el presente trabajo y que, para el periodo mencionado, se sitúan entre el $40 \%$ y el 50\%. Aun así, las diferencias muestrales entre ambos estudios impiden ir más allá a la hora de valorar este contraste.

14 Recuérdense los datos recogidos por Rodríguez Molina en textos literarios del siglo $\mathrm{XV}$, en los que la forma ansí apenas rebasa el 6\%. 
desaparecer o, en el mejor de los casos, quedar relegada a contextos muy restringidos, como vimos que sucedió a partir del siglo XVIII.

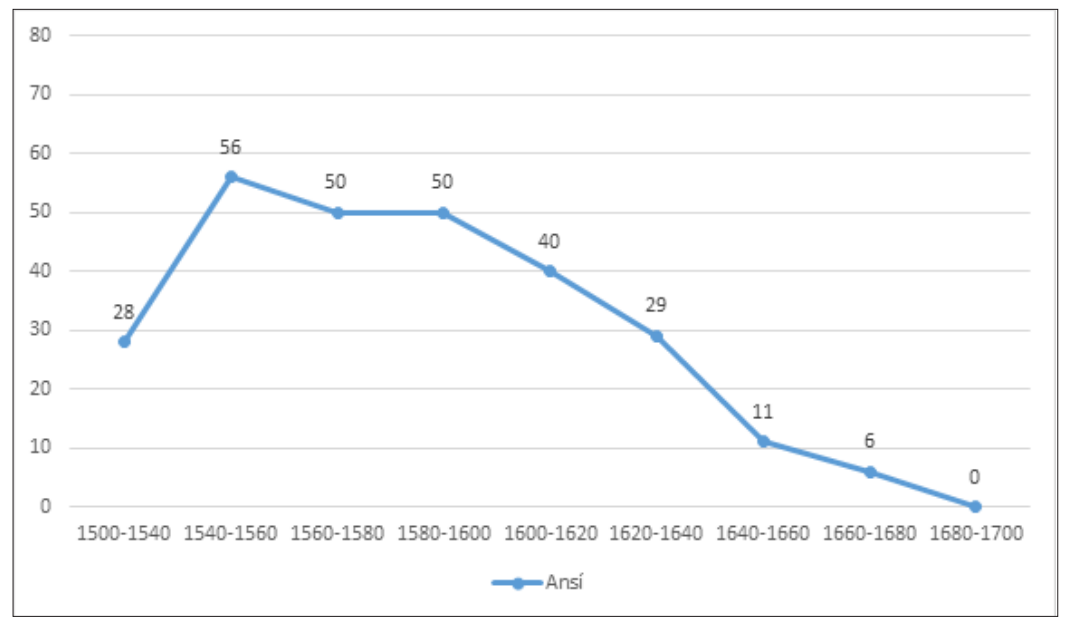

Gráfico 1: Distribución de los usos de ansí en periodos de veinte años entre 1500 y $1700(\%)^{15}$

\subsection{USOS LINGÜÍSTICOS DEL ADVERBIO}

La Tabla 2 muestra la distribución de la variable lingüística en los diferentes empleos descritos más arriba (§ 3.1).

15 Dada la escasez de ocurrencias de la variable en los dos primeros periodos y la similitud de sus proporciones, las agrupamos en uno solo. 


\begin{tabular}{|l|c|c|c|}
\hline \multicolumn{1}{|c|}{ Categorías } & $\mathbf{N}$ & $\mathbf{\%}$ & $\mathbf{\Sigma}$ \\
\hline $\begin{array}{l}\text { Marcador } \\
\text { (consecuencia) }\end{array}$ & 478 & 42 & 1135 \\
\hline Adverbio manera & 236 & 43 & 553 \\
\hline $\begin{array}{l}\text { Conjunción } \\
\text { copulativa }\end{array}$ & 85 & 38 & 221 \\
\hline Así que & 59 & 49 & 121 \\
\hline Así mismo & 38 & 41 & 93 \\
\hline Loc. Adv. Temp. & 11 & 50 & 22 \\
\hline Loc. Adv. Compa. & 10 & 47 & 21 \\
\hline Interjección & 9 & 47 & 19 \\
\hline Otras & 10 & 47 & 21 \\
\hline Total & 936 & 42 & \\
\hline
\end{tabular}

Tabla 2: Distribución de los usos de ansí por categorías

Si tomamos inicialmente en consideración las frecuencias totales del adverbio, expuestas en la última columna, varios datos llaman la atención. En primer lugar, cabe resaltar el hecho de que los empleos mayoritarios no corresponden, como cabía esperar, a la función deíctica (exofórica o endofórica) $(N=553)$ que, como vimos, se ha considerado más básica y antigua, y a partir de la cual se habrían derivado las demás. Aunque esto pudo ser así en periodos previos de la historia, a partir del siglo XVI, el papel fundamental del adverbio pasa a ser el de marcador discursivo $(N=1135)$, casi siempre precedido por la conjunción $y$. Rodríguez Molina (2014a: 915) señala en relación con este asunto que: "a partir del siglo XVII se produce una verdadera eclosión de los empleos de así como marcador discursivo", si bien no aporta más detalles acerca de su posible prelación con respecto a los empleos como adverbio de manera. Sin embargo, los resultados de nuestro estudio permiten confirmar este hecho completamente. Al mismo tiempo, un análisis de la evolución de estos usos como marcador discursivo, como el que revela el Gráfico 2, muestra que esa eclosión sobresale especialmente entre 1550 y 1650 , coincidiendo, como hemos visto, con el momento de mayor esplendor de la forma ansi. 


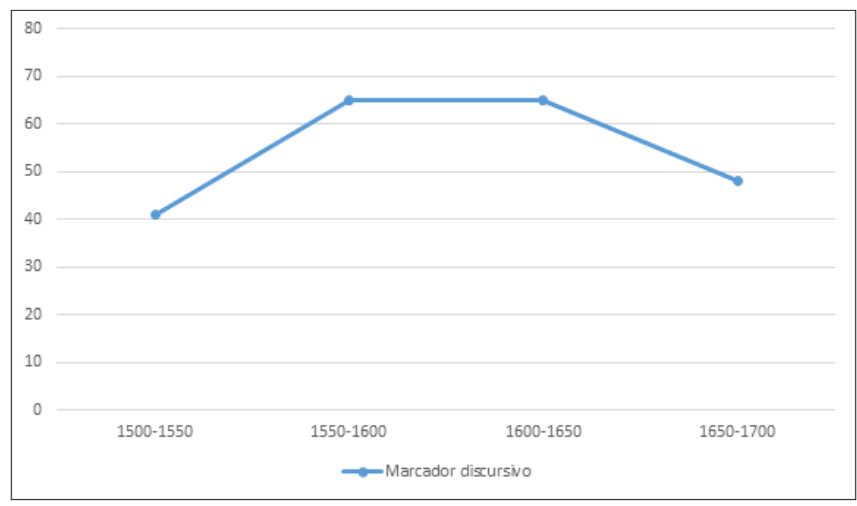

Gráfico 2: Evolución de los usos de la variable como marcador discursivo

El resto de empleos del adverbio obtiene frecuencias que se sitúan claramente por debajo de las dos funciones reseñadas. Sin embargo, los datos de la Tabla 2 arrojan cifras nada desdeñables de los empleos del adverbio en locuciones conjuntivas de adición $(N=221)$, consecutivas $(N=121)$ o de la locución adverbial con el adjetivo mismo $(N=93)$. Ya a distancia se aparecen otros usos locucionales tanto comparativos $(N=22)$ como temporales $(N=21)$, así como algunos empleos interjectivos $(N=19)$. Finalmente, en el grupo de Otros $(N=21)$ se agrupan otras funciones todavía más esporádicas, como las descritas anteriormente (ver $\S 3.1$ ). En definitiva, estos resultados confirman la polivalencia del adverbio en el español de los Siglos de Oro.

Por lo que respecta a la distribución de ansí, la Tabla 2 destaca también por ofrecer unos datos bastante uniformes, de tal manera que las proporciones obtenidas en cada una de las categorías se sitúan en casi todos los casos en una horquilla que oscila entre el $40 \%$ y el $50 \%$, cercana, pues, a la media global de la variante. Los resultados son especialmente parejos en los usos mayoritarios, como el adverbio de manera (43\%) y la marcación discursiva (42\%), que, por sí solos, representan, como hemos visto, el 75\% de todas las ocurrencias de la variable.

Algunos datos recogidos en este estudio difieren de lo advertido en investigaciones previas. Así, del Corral (2013: 3644) dice no encontrar ningún ejemplo del marcador (y) así con la forma ansí en las cartas oficiales ecuatorianas del siglo XVII. Al respecto, señala también que este hecho contrasta con la conservación de la consonante nasal en la combinación ansimismo, de la que se encuentran vestigios hasta mediados de esa centuria (Sánchez 1997: 340 y este trabajo), y especula con la posibilidad de que, frente a este, el conector (y) asní ya se hubiera perdido en el XVII. Sin embargo, en nuestro corpus encontramos hasta 70 ejemplos diferentes de 
este nexo supraoracional en los materiales del siglo XVII, uno de los cuales, incluido en una carta fechada en 1637, se muestra a continuación.

(38) En otras ocasiones escrito a vm. por estenso de mis desdichas y trabajos que e pasado en mis largas jornadas y en todo este reino del Pirú $y$ ansi en ésta quise escusar de hacelle sauidor de lo pasado... (Vida y fortuna del emigrante navarro a Indias, 1637)

Estas cifras contrastan, evidentemente, con las mucho más numerosas halladas en los textos del XVI, pero revelan al mismo tiempo que los empleos de ansí como marcador discusivo no habían desaparecido en el XVII. Ahora bien, lo cierto es que, conforme fue transcurriendo la centuria, estos usos irían languideciendo, hasta el punto de que tan solo siete de esos setenta casos corresponden a la segunda mitad.

\subsection{EL CONDICIONAMIENTO LINGÜÍSTICO DE ANSI}

La relativa uniformidad que hallamos en las distribuciones reseñadas a propósito de ansí se ven confirmadas en lo esencial por el análisis de regresión, cuyos resultados se detallan en la Tabla 3.

\begin{tabular}{|l|c|c|c|c|}
\hline & $\mathbf{N}$ & $\mathbf{\%}$ & $\boldsymbol{\Sigma}$ & $\mathbf{P .}$ \\
\hline Sentido & & & & \\
\hline Adición & 125 & 39 & 318 & - \\
\hline Consecuencia & 538 & 43 & 1256 & - \\
\hline Manera & 236 & 42 & 555 & - \\
\hline Otros & 37 & 48 & 77 & - \\
\hline Categoría & & & & \\
\hline Adverbio & 757 & 42 & 1794 & - \\
\hline Otras & 179 & 43 & 412 & - \\
\hline Cotexto & & & & \\
\hline$Y$ precedente & 488 & 42 & 1164 & - \\
\hline Resto & 448 & 43 & 1042 & - \\
\hline Función & & & & \\
\hline Atributo & 76 & 49 & 156 & .59 \\
\hline CCM & 160 & 40 & 397 & .41 \\
\hline Posición & & & & \\
\hline Antepuesto & 135 & 41 & 327 & - \\
\hline
\end{tabular}




\begin{tabular}{|c|c|c|c|c|}
\hline Pospuesto & 101 & 44 & 226 & - \\
\hline \multicolumn{5}{|l|}{ Sexo } \\
\hline Hombre & 836 & 42 & 1994 & - \\
\hline Mujer & 100 & 47 & 212 & - \\
\hline \multicolumn{5}{|l|}{ Tenor } \\
\hline Cercana & 479 & 45 & 1064 & - \\
\hline Intermedia & 161 & 44 & 363 & - \\
\hline Distante & 296 & 38 & 779 & - \\
\hline \multicolumn{5}{|l|}{ Estatus } \\
\hline Alto & 42 & 19 & 225 & .13 \\
\hline Medio & 329 & 39 & 851 & .62 \\
\hline Bajo & 565 & 50 & 1130 & .80 \\
\hline \multicolumn{5}{|l|}{ Norte-sur } \\
\hline Centro-meridionales & 502 & 45 & 1096 & - \\
\hline Norteñas & 327 & 38 & 858 & - \\
\hline \multicolumn{5}{|l|}{ Oeste-este } \\
\hline Centro-occidentales & 703 & 45 & 1552 & .67 \\
\hline Orientales & 103 & 28 & 364 & .32 \\
\hline \multicolumn{5}{|l|}{ Contexto migra. } \\
\hline Europa & 107 & 28 & 385 & .35 \\
\hline América & 829 & 45 & 1821 & .65 \\
\hline Década & & & & -4.118 \\
\hline
\end{tabular}

$N=2206$; intercept: 63.35; overall proportion: 0.42; log.likelihood: -996.312; AICc: 2004.662; Dxy.total: 0.94

Tabla 3: Contribución de los predictores lingüísticos y extralingüísticos a la selección del adverbio ansí en textos de los siglos XVI y XVII (variable aleatoria: escritor)

En efecto, los datos de la tabla muestran cómo la variable lingüística apenas se ve condicionada por factores estructurales. Así, ni el valor semántico (sentido), ni la categoría gramatical o el cotexto sintagmático muestran diferencias significativas en su interior. Tan solo entre los usos deícticos del adverbio se aprecia una pequeña contribución de la función sintáctica: la selección de ansí se ve favorecida levemente cuando el adverbio desempeña una función argumental, como la de atributo o predicativo $(.59 ; 49 \%)$, mientras que un efecto desfavorecedor equivalente lo ejerce el papel de adjunto o complemento circunstancial de modo $(.41 ; 40 \%)$. Con todo, el 
rango obtenido por el predictor es de escasa entidad (18), lo que revela que su incidencia es limitada ${ }^{16}$. Por el contrario, entre esos mismos adverbios, la posición antepuesta o pospuesta al verbo se muestra de nuevo completamente irrelevante.

Todo ello confirma la considerable equivalencia sintáctico-semántica de las dos variantes en los Siglos de Oro, hasta el punto de que podría hablarse de una (casi) sinonimia estructural (del Barrio 2017: 252). Ahora bien ¿sucede lo mismo en el plano socioestilístico? Los resultados que se detallan a continuación demuestran que ello no es así, y que la distribución de ansíse vio claramente afectada por factores extralingüísticos, sobre todo, diastráticos y dialectales.

\subsection{FACTORES EXTRALINGÜÍSTICOS}

Los resultados de la tabla 3 muestran, en efecto, que la variable lingüística se vio condicionada en mucha mayor medida por condicionantes extralingüísticos que puramente estructurales, un hecho poco habitual entre los fenómenos de variación gramatical (Blas Arroyo 2005, Tagliamonte 2012), pero comprensible si tenemos en cuenta que, en el presente caso, nos enfrentamos ante una variación de naturaleza morfo-léxica. En estos casos, la elección de una u otra forma puede depender antes de preferencias y usos derivados de la estructura social, que de verdaderas diferencias estructurales entre las variantes en competición.

Aun así, entre los predictores considerados, algunos no encuentran suficiente fuerza empírica como para superar el umbral de significación requerido. En todo caso, a ello puede contribuir en ocasiones la existencia de importantes desequilibrios muestrales, como los que se aprecian, por ejemplo, en relación con el sexo de los escritores. Así, de todos los ejemplos disponibles, apenas un $10 \%(N=212)$ corresponde a muestras femeninas. Ello, unido a que las proporciones de ansí obtenidas entre estas (47\%) son cercanas a las encontradas entre los hombres (42\%), descarta la existencia de diferencias generolectales en relación con el adverbio, al menos con los datos disponibles.

\footnotetext{
16 En la sociolingüística variacionista, una de las medidas para calcular la importancia de un predictor es su rango, una cifra que se obtiene tras restar los valores probabilísticos entre los factores más y menos favorecedores, respectivamente (Tagliamonte 2012). En el presente caso, el valor de 18 se consigue al comparar el peso de la función argumental (.59) y el del resto de funciones (.41).
} 
Notablemente más equilibradas, y con diferencias frecuenciales algo mayores, son las muestras relacionadas con la división dialectal entre individuos procedentes de regiones norteñas y centro-meridionales. Como se recordará, para el análisis de este predictor llevamos a cabo un análisis específico, en el que tan solo se consideraron las ocurrencias de la variable cuyo autor tuviera un origen conocido (ver § 3.3). Los resultados de ese análisis confirmaron los obtenidos en la muestra general, al tiempo que descartaron la incidencia significativa de este factor, pese a unas frecuencias que apuntaban a un mayor índice de ansí en las comunidades de habla centromeridionales ( $45 \%$ ) que en las norteñas (38\%). Ciertamente, las diferencias no son abultadas, pero serían dignas de consideración en un estudio futuro a partir de una muestra más amplia, más aún, cuando otros estudios han advertido una preferencia por estas soluciones en obras literarias escritas por autores toledanos y andaluces (Rodríguez Molina 2015: 1062).

Lo mismo sucede en el plano diafásico. La distinción entre tres grados en el tenor de los textos no es seleccionada tampoco por el estadístico de regresión, y ello pese a que la distribución de las frecuencias muestra un patrón lineal, en el que los mayores usos de ansí se detectan en la comunicación más íntima y espontánea (cercana $(45 \%)$, seguidos de cerca por la intermedia (44\%), y con los textos más distantes y formales $(38 \%)$, como los inicialmente menos proclives al uso de la variante. Ni siquiera un reanálisis, en el que los dos primeros grados se agrupan en un solo bloque y se oponen al último supera el umbral de significación. Sea como sea, la menor presencia de ansí entre los textos más formales quizá pueda ponerse en relación con las cifras encontradas por Rodríguez Molina (2015) en textos literarios, cuyos índices en el siglo XVI (25\%) se sitúan a considerable distancia de los obtenidos en esta investigación en textos más cercanos al polo de la inmediatez comunicativa. En el mismo sentido, aunque con una muestra más reducida, del Barrio (2017: 257) ofrece cifras del 36\% en los textos de la Cancillería, y más bajas todavía en la esfera eclesiástica (18\%) en el momento de mayor apogeo de la variante (1580-1620), lo que invita a proseguir en el futuro con esta línea de investigación en torno a los condicionantes diafásicos de este fenómeno de variación. Más aún cuando nuestros datos y los ofrecidos por este autor en torno a los contextos más informales son tan dispares. Así, en el periodo mencionado, la presencia de ansí en los entornos más familiares y cercanos en nuestro corpus asciende al $50 \%(N=853)$, frente al magro $23 \%(N=61)$ obtenido por del Barrio (2017) a partir de los materiales de CODEA.

Frente a los factores considerados hasta el momento, el estatus social se revela, sin embargo, como un predictor robusto (rango 67), que establece una nítida distribución acorde con la jerarquía social del periodo áureo. Según 
esta, la variante ansí es claramente favorecida por el estrato más bajo (.80; $50 \%)$, seguido a cierta distancia por el intermedio $(.62 ; 39 \%)$, y a mucha más por la élite social $(.13 ; 19 \%)$, que se revela como el sector menos proclive al empleo de la forma novedosa. Estos datos, sin embargo, sufren algunos cambios significativos entre una centuria y otra. Así, en el siglo XVI, la distribución lineal observada es idéntica (Alto: 26\%; Medio: 48\%; Bajo: $53 \%$ ), pero la distancia entre los grupos es menor, especialmente entre los grupos bajo e intermedio. Ello induce a pensar que el cambio lingüístico favorable a la forma ansí, que se desarrolla de una manera especialmente abrupta a partir de la cuarta década del siglo XVI, bien pudo desarrollarse como un cambio desde abajo, impulsado por los sectores medio-bajos (Penny 2000: 42, 119; Labov 2007: 346; Conde Silvestre 2007: 300-302), y al que se sumarían de una manera más tímida las élites sociales, más proclives al empleo de la variante más tradicional. Asimismo, estos resultados se ajustan a algunos de los advertidos por Rodríguez Molina (2015) en su investigación sobre obras del siglo XVI. De hecho, quizá no sea casualidad que las proporciones de ansi en obras literarias ambientadas y protagonizadas por personajes populares (Lazarillo (47\%), La lozana andaluza (77\%), los Pasos de Lope de Rueda (33\%) sean superiores a las que hallamos en los escritos de algunos miembros de las elites culturales (Diálogo de Valdés $(20 \%)$, Floresta de Santacruz (21\%), Brevísima de Bartolomé de las Casas (3\%) ${ }^{17}$.

Sin embargo, a partir del XVII, pero en especial de su segunda mitad, se produce una clara reacción contraria a ese cambio que tanto éxito había cosechado en la centuria anterior. En esa reacción, favorable, pues, al regreso a la tradicional así, las élites adquieren un especial protagonismo, con cifras de ansí que apenas alcanzan ya el 7\%. Incluso esta vuelta a la ortodoxia será imitada también, aunque en considerable menor medida, por los estratos medios $(24 \%)$ y bajos (31\%).

Finalmente, el fenómeno de variación que nos ocupa muestra también una clara correlación con dos factores dialectales. El primero de ellos es el que opone a las comunidades de habla centro-occidentales de las orientales, confirmando así el perfil geolectal advertido en la bibliografía previa (Corominas y Pascual 1980-1991; Rodríguez Molina 2015; del Barrio 2017), y al que nos referíamos más arriba con más detalle (ver $\S 3.3$ ). En efecto, del reanálisis efectuado exclusivamente con los ejemplos cuyo origen dialectal se conoce, se desprende que la variante ansí tuvo una especial difusión en el periodo áureo en las comunidades del centro y el oeste de

17 Una excepción, ya reseñada, es la representada por el caso singular de Villalón en su Gramática, con un empleo sistemático de ansí. 
la península $(.67 ; 45 \%)$, mientras que su distribución en las orientales fue significativamente menor $(.32 ; 28 \%)$. Aunque de nuevo nos hallamos ante un predictor mal distribuido muestralmente ${ }^{18}$, las diferencias estadísticas son esta vez suficientemente nítidas y contundentes (rango 35).

Lo mismo sucede, finalmente, con el contexto en que fueron escritos los textos, muchos de los cuales se redactaron en América, probablemente en condiciones de contacto interdialectal más extremas que los escritos desde España. Los resultados permiten advertir una diferencia significativa entre el contexto americano $(.65 ; 45 \%)$ y el europeo $(.35 ; 28 \%)$, unos datos que coinciden con observaciones previas que advertían de un mayor mantenimiento de las soluciones con ansí en Hispanoamérica que en España. Con todo, es revelador que el factor tenga un rango significativamente menor que el predictor anterior (20) y ello porque un análisis más detallado por siglos, como el que muestra el gráfico 3, permite comprobar que ese mantenimiento de ansí tiene lugar preferentemente en el subcorpus correspondiente al siglo XVII, pero no en el XVI, el de máxima eclosión de la variante, $\mathrm{y}$ en el que las proporciones entre un contexto y otro aparecen mucho más igualadas.

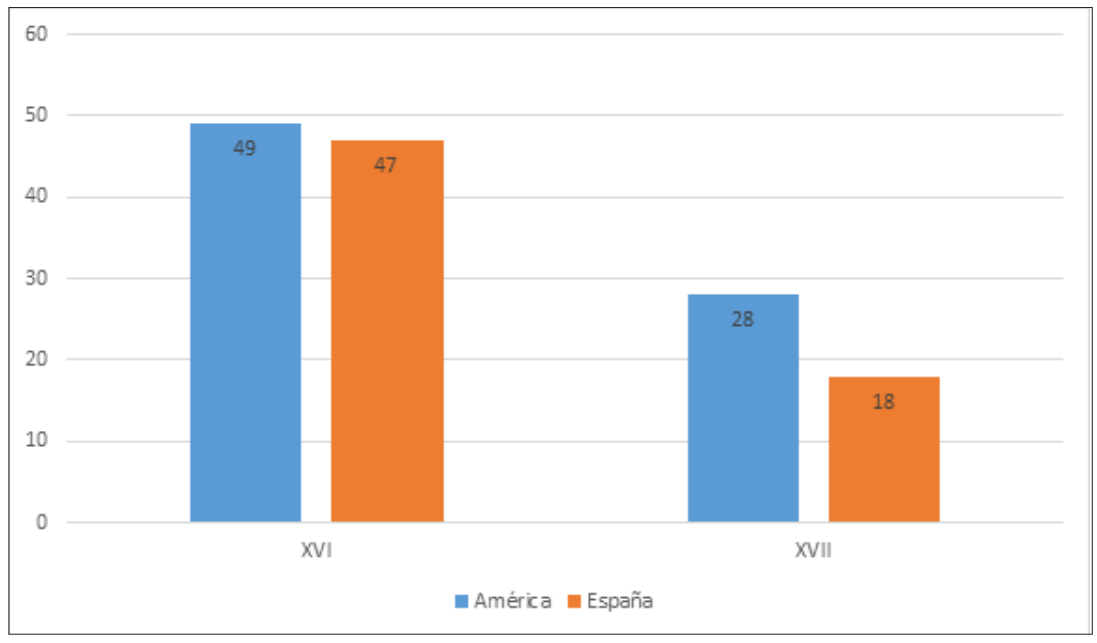

Gráfico 3: Distribución de los usos de ansí en comunidades de habla americanas y españolas en los siglos XVI y XVII (\%)

18 La razón hay que encontrarla en el hecho de que una parte muy importante de los textos incluidos en el corpus está relacionada de una u otra manera con la conquista y colonización de América, empresa en la que los individuos de la antigua Corona de Aragón tuvieron un protagonismo menor durante los primeros siglos. 


\section{CONCLUSIONES}

Varias conclusiones se derivan de los resultados obtenidos en el presente estudio que, en el marco de la sociolingüística histórica y a partir de materiales próximos al polo de la inmediatez comunicativa, pretendía analizar el condicionamiento variable del adverbio ansí en los Siglos de Oro. Algunas vienen a confirmar hipótesis formuladas previamente a propósito de este adverbio. En primer lugar, está el hecho evidente de que, en el español clásico, ansí conoció un periodo de apogeo como nunca antes había tenido, y todavía lo tendría menos a partir del siglo XVIII, cuando caería en desuso, quedando sus empleos restringidos a enclaves dialectales y sociolectales mucho más limitados. De hecho, los datos de este estudio superan las cifras halladas en recuentos previos a partir de textos más formales, lo que lleva a pensar que su uso en la lengua vernácula debió de ser ciertamente amplio. Al mismo tiempo, se confirma el perfil dialectal del adverbio, que, aun hallándose en los textos escritos en toda la geografía española, tuvo como principal área de difusión las zonas centro-occidentales de la península.

Ahora bien, los resultados de esta investigación aportan también algunas novedades dignas de atención. No está entre las menos importantes el modo en que se produjo la evolución de ansí a lo largo de este periodo, con un claro perfil curvilíneo, que revela la existencia de varios momentos, tanto en su éxito inicial como en su fracaso posterior. Partiendo de la hipótesis de que un incremento significativo en los usos del adverbio se habría producido ya en las últimas décadas del siglo $\mathrm{XV}$, este siguió creciendo de una manera significativa a lo largo de la siguiente centuria. En la práctica, a partir de 1540 la variante llegaría a duplicar sus empleos con respecto al periodo inmediatamente anterior, entrando así en una fase de crecimiento abrupto, con índices que llegaron a disputar la primacía a la forma así, y que se mantendrían hasta el final del siglo XVI y comienzos del XVII. Con todo, a partir de este momento se inició un movimiento contrario, de regreso a la ortodoxia de la variante tradicional, que se vio ralentizado todavía durante las primeras décadas, pero que se aceleraría a partir de mediados de ese siglo. Desde entonces, y hasta el final de esa centuria, las manifestaciones de la forma vernácula fueron descendiendo con la misma brusquedad con que habían aumentado un siglo antes -aunque menos en las variedades americanas que en las europeas-, hasta cerrar la etapa clásica con índices prácticamente nulos, que presagiaban la actitud negativa a la que se vería sometido el adverbio durante el periodo ilustrado. Más aún, de lo advertido en este trabajo se desprende que la caída en desgracia de la variante, que alguna vez se ha ubicado en el siglo XVIII, pudo comenzar 
ya en las postrimerías del XVII, de tal manera que la recién estrenada Real Academia habría venido a certificar una censura que ya se había producido en la sociedad, especialmente en los estratos privilegiados.

De hecho, en esa particular evolución de ansí, pudo tener una influencia decisiva el estatus social de los hablantes. En el estudio cuantitativo llevado a cabo, este predictor es seleccionado en el análisis de regresión logística y muestra una nítida distribución lineal, paralela al estatus de los escritores. Así, en la cúspide de usos de la forma vernácula aparece sistemáticamente la base social, seguida por los sectores intermedios, y a distancia ambos de los estratos sociales más elevados, que, a la luz de nuestros datos, mostraron siempre una mayor prevención hacia esta variante. Con todo, la aversión hacia ansí se incrementaría entre esas élites durante el siglo XVII, especialmente a partir de su segunda mitad, lo que invita a pensar que fueron ellas las encargadas de reaccionar en contra de un adverbio que, aparentemente, se había difundido un siglo atrás como un característico cambio desde abajo. Como se ha advertido en la tradición sociolingüística, estos cambios no solo son impulsados por las clases medio-bajas, sino que, al menos en sus primeras etapas, suelen circular por debajo del nivel de la conciencia. Y el hecho de que el tenor de los textos no haya sido seleccionado como significativo por el estadístico de regresión invita a pensar que la difusión del adverbio se produjo de una manera relativamente uniforme, con escasa incidencia del componente estilístico. En ese sentido, pues, es posible que, al menos durante el XVI, ansí pudo funcionar como un indicador sociolingüístico, sensible a la variación sociolectal, pero no tanto a las diferencias de registro o estilo.

Esta misma uniformidad se aprecia en el condicionamiento estructural de la variable, lo que sugiere una práctica sinonimia sintáctico-semántica entre ansí y así durante todo este periodo. Tan solo en el seno de los usos deícticos del adverbio se aprecia una leve incidencia de la función sintáctica, con empleos más favorables de ansí entre las funciones argumentales que entre las no argumentales. Todo ello hace que nos enfrentemos a un tipo singular de variable morfosintáctica, condicionada casi exclusivamente por factores extralingüísticos, un resultado poco habitual en este tipo de variables, pero explicable quizá por el hecho de tratarse de un caso de variación en el que el componente léxico es tan importante como el gramatical. En consecuencia, parece que, durante una buena parte del periodo clásico, pero especialmente durante el siglo XVI, ansí estuvo francamente "de moda" entre los hablantes españoles, pero, como pasa tantas veces, esta moda se fue diluyendo en la centuria siguiente, hasta llegar prácticamente a desaparecer. 


\section{REFERENCIAS BIBLIOGRÁFICAS}

Alonso, Amado. 1930. Asín, asina, ansí, ansina. En Aurelio M. Espinosa (ed.). Estudios sobre el español de Nuevo Méjico, pp. 411-416. Buenos Aires: Imprenta de la Universidad de Aires.

Álvarez, Alfredo I. 1999. Las construcciones consecutivas. En Ignacio Bosque y Violeta Demonte (eds.). Gramática Descriptiva de la Lengua Española, pp. 3739-3804, Madrid: Espasa-Calpe.

Blas Arroyo, José Luis. 2005. Sociolingüistica del español. Madrid: Cátedra.

Blas Arroyo, José LuIS y JuAn GonZÁLEZ. 2019. Escritura, oralidad y variación: reanálisis de la alternancia allí/allá a partir de un corpus epistolar del siglo XVI. Zeitschrift für Romanische Philologie 135 (4): 971-1006.

Blas Arroyo, José Luis, Margarita Porcar, Mónica Velando y Javier Vellón. 2019. Sociolingüistica histórica del español: Tras las huellas de la variación y el cambio lingüistico a través de textos de inmediatez comunicativa. Madrid/Frankfurt: Iberoamericana/Vervuert.

Bosque, Ignacio. 1989. Las categorías gramaticales. Madrid: Síntesis.

Cano Aguilar, Rafael. 2007. Conectores de discurso en el español del siglo XVI. Lexis $31(1 / 2): 5-45$.

Corominas, Joan y José Antonio Pascual. 1980-1991. Diccionario crítico etimológico castellano e hispánico. Madrid: Gredos.

Conde Silvestre, Juan Camilo. 2007. Sociolingüistica histórica. Madrid: Gredos.

Correas, Gonzalo. 1909 [1627]. Arte grande de la lengua castellana (editado por el Marqués de la Viñaza). Madrid: RAE.

Cuervo, Rufino José. 1886-1998. Diccionario de construcción y régimen de la lengua castellana (continuado y editado por el Instituto Caro y Cuervo). Bogotá: Instituto Caro y Cuervo.

DEl BARRio, Florencio. 2017. Piezas léxicas y variación morfosintáctica en la Historia del español. Tres casos en el español de los Siglos de Oro (1581-1620). En Florencio del Barrio (ed.). Palabras Vocabulario Léxico. La lexicología aplicada a la didáctica y a la diacronía, pp. 251-266. Venezia: Edizioni Ca Foscari.

DEL CoRral, ElENA. 2013. La partícula (y) asi en cartas oficiales ecuatorianas (XVI-XVII). En Emili Casanova y Cesáreo Calvo (eds.). Actas del XXVI Congreso Internacional de Lingüística y de Filología Románicas. Vol. 6, pp. 429-440. Berlín: de Gruyter.

ElSPASS, STEPHAN. 2012. The use of private letters and diaries in sociolinguistic investigation. En Juan M. Hernández-Campoy y Juan C. Conde-Silvestre (eds.). The Handbook of Historical Sociolinguistics, pp. 156-169. Malden, MA: Wiley-Blackwell.

Fernández Alcaide, Marta. 2009. Cartas de particulares en Indias del siglo XVI. Edición y estudio discursivo. Madrid / Frankfurt am Main: Iberoamericana / Vervuert.

Fernández Álvarez, Manuel. 2004. Sombras y luces en la España imperial. Barcelona: Planeta.

GiRÓn AlCONChel, José Luis. 2004. Cambios gramaticales en los Siglos de Oro. En Rafael Cano Aguilar (coord.). Historia de la lengua española, pp. 859-893. Barcelona: Ariel.

Johnson, DANiEl EzRa. 2009. Getting off the GoldVarb standard: Introducing Rbrul for mixed-effects variable rule analysis. Language and Linguistics Compass 3 (1): 359-383.

Keniston, Hayward. 1937. The syntax of Castillian prose. The sixteenth century. Chicago: The University of Chicago Press. 
Labov, William. 1972. Sociolinguistics Patterns. Philadelphia: Pennsylvania University. 2007. Transmission and diffusion. Language 83: 344-387.

Lope Blanch, Juan M. (ed.). 1969. Juan de Valdés: Diálogo de la lengua. Madrid: Castalia.

Martín Zorraquino, María Antonia y José Portolés Lázaro. 1999. Los marcadores del discurso. En Ignacio Bosque y Violeta Demonte (eds.). Gramática Descriptiva de la Lengua Española, pp. 4051-4213. Madrid: Espasa-Calpe.

Medina Morales, Francisca. 2005. La lengua del Siglo de Oro. Un estudio de variación lingüística. Granada: Universidad de Granada.

Menéndez Pidal, Ramón. 1976. Orígenes del español. Madrid: Espasa-Calpe.

Nevalainen, Tertu y Helena Raumolin-Brunberg. 2003. Historical Sociolinguistics. London: Longman.

Octavio de Toledo y Huerta, Alvaro y Cristina SÁnchez LóPez. 2009. Cuantificadores II. Cuantificadores interrogativos y exclamativos. En Concepción Company (dir.). Sintaxis histórica de la lengua española. Segunda parte: La frase nominal, pp. 961-1072. México: Fondo de Cultura Económica-Universidad Nacional Autónoma.

OESTERREICHER, WULF. 2004. Textos entre inmediatez y distancia comunicativas. El problema de lo hablado escrito en el Siglo de Oro. En Rafael Cano Aguilar (coord.). Historia de la lengua española, pp. 729-769. Barcelona: Ariel.

Penny, Ralph. 2000. Variation and Change in Spanish. Cambridge: Cambridge University Press.

Real ACAdEMia EsPañola (RAE) / ASALE. 2009. Nueva gramática de la lengua española. Madrid: Espasa-Calpe.

Rodríguez Molina, JAVIER. 2014a. Adverbios y locuciones adverbiales de manera. En Concepción Company (dir.). Sintaxis histórica de la lengua española. Tercera parte: Adverbio, preposiciones y conjunciones. Relaciones interoracionales, pp. 733-937. México: UNAM.

2014b. La gramática oculta de la polaridad afirmativa enfática en español antiguo. RILCE 30 (3): 861-915.

2015. El adverbio asi en español medieval: variantes morfonéticas. En José María García Martín (dir.). Actas del IX Congreso Internacional de Historia de la Lengua Española (Cádiz, 2012), vol. 1, pp. 1049-1064. Madrid / Frankfurt am Main: Iberoamericana /Vervuert.

SÁnchez, Juan Pedro. 1997. Aproximación histórica al español de Venezuela y Ecuador durante los siglos XVII y XVIII. Valencia: Universitat de València / Tirant lo Blanch.

SAntos Río, Luis. 2003. Diccionario de partículas. Salamanca: Luso-Española de Ediciones.

SCHNEIDER, EDGAR. 2013. Investigating variation and change in written documents. En Jack K. Chambers, Peter Trudgill y Nathalie Schilling-Estes (eds.). The Handbook of Language Variation and Change, pp. 57-81. Oxford: Blackwell.

Seco, Manuel, Olimpia de Andrés y Gabino Ramos. 1999. Diccionario del español actual. Madrid: Aguilar.

Tagliamonte, Sali A. 2012. Variationist Sociolinguistics. Change, Observation, Interpretation. Malden, MA: Wiley-Blackwell.

Villalón, CRistóbal DE. 1558. Gramática castellana. Amberes: Guillermo Simón.

\section{ANEXo (CORPUS)}

Ahumada Batlle, Eulàlia. 2003. Epistolaris d'Hipòlita Roís de Liori i d'Estefania de Requesens. València: Universitat de València. 
Aramburu Zudaire, José Miguel. 1999. Vida y fortuna del emigrante navarro a Indias, siglos XVI-XVII. Pamplona: Gobierno de Navarra.

BouzÁ Álvarez, Fernando. 2001. Ocho cartas de placer de palacio y una de disparates de Corte. En Fernando Bouzá (ed.). Corre manuscrito: una historia cultural del Siglo de Oro, pp. 199-214. Madrid: Marcial Pons.

Carande, Ramón. 1944. Cartas de mercaderes. Moneda y crédito 9: 13-50.

Company Company, Concepción. 1994. Documentos lingüísticos de la Nueva España. Altiplano central. México: UNAM.

Cortijo Ocaña, Adelaida. 2002. Entre Luisa de Carvajal y el conde de Gondomar. Nuevos textos sobre la persecución anticatólica en Inglaterra (1612-1614). Voz y letra: Revista de literatura 2: 17-59.

Cortijo Ocaña, Antonio y Adelaida Cortijo Ocaña. 2003. Cartas desde México y Guatemala, 1540-1635. El proceso Díaz de la Reguera. Documentos. Cáceres: Universidad de Extremadura.

Crespí de Valldaura, Gonzalo. 2012. Diario del Señor D. Cristóbal Crespí desde el día en que fue nombrado presidente del Consejo de Aragón: 9 de junio 1652. Madrid: Boletín Oficial Del Estado.

Crosby, JAmes. 2005. Nuevas cartas de la última prisión de Quevedo. Woodbridge: Tamesis Books.

De Stefano, Luciana y María Josefina Tejera. 2006. Documentos para la historia del español de Venezuela, Siglo XVI. Caracas: Universidad Central de Venezuela (publicación en CD-ROM).

EBERENZ, ROLF y MARIELA DE LA TORRE. 2003. Conversaciones estrechamente vigiladas: interacción coloquial y español oral en las actas inquisitoriales de los siglos XV a XVII. Zaragoza: Pórtico.

Fernández Alcaide, Marta. 2009. Cartas de particulares en Indias del siglo XVI. Edición y estudio discursivo. Frankfurt: Vervuert.

Fontanella de Weinberg, María Beatriz. 1993. Documentos para la historia lingüística de Hispanoamérica. Vol. I. Madrid: BRAE.

FraGo, JuAn A. 1999. Notas sobre el español antillano del siglo XVI en cartas de emigrados andaluces. En Amparo Morales (ed.). Estudios de lingüistica hispánica. Homenaje a María Vaquero, pp. 250-262. San Juan: Universidad de Puerto Rico.

Gómez Seibane, Sara, Isasi Martínez, Carmen y Sesmero, Enriqueta. 2007. Bilbao en sus documentos (1544-1694). Deusto: Universidad de Deusto.

GuZmán Riverón, Martha. 2007. Textos del Caribe (siglos XVI y XVII). Munich: Universidad Ludwig-Maximiliams.

Hidalgo Nuchera, Patricio. 2006. Entre Castro del Río y México. Correspondencia privada de Diego de la Cueva y su hermano Juan, emigrante en Indias (1601-1641. Córdoba: Universidad de Córdoba.

JACOBS, Auke Pieter. 1995. Los movimientos migratorios entre Castilla e Hispanoamérica durante el Reinado de Felipe III, 1598-1621. Amsterdam: Rodopi.

López Benito, Clara IsABel. 2000. La cosmovisión de una mujer salmantina emigrada a las Indias y vinculada con los Montejo de Yucatán, a través de sus cartas privadas. Salamanca, Revista de Estudios 44: 315-367.

López de Mendoza, Íñigo, María José Osorio Pérez, José Szmolka Clares y María Amparo Moreno Trujillo. 1996. Epistolario del conde de Tendilla (1504-1506). Granada: Universidad de Granada.

Lorenzo Pinar, Francisco Javier y Luis Vasallo Toranzo. 1996. Diario de Antonio Moreno de la Torre. Zamora, 1673-79. Vida cotidiana en una ciudad española durante el siglo XVII. Zamora: Instituto de Estudios Zamoranos. 
Martínez Hernández, SANTiago. 2012. El diario del marqués de Osera (1657-1659. Madrid: Edición Doce Calles.

Martínez Martínez, María del CARMen (ED.). 2007. Desde la otra orilla. Cartas de Indias en el Archivo de la Real Chancillería de Valladolid, siglos XVI-XVIII. León: Junta de Castilla y León.

Navarro Bonilla, Diego. 2003. Del corazón a la pluma: archivos y papeles privados femeninos en la Edad Moderna. Salamanca: Universidad.

NúÑEZ, FraY L. 1914. Dos cartas de sor Isabel de Baena a la duquesa del Infantado. Archivo Ibero-americano 1(4): 322-325.

Otte, EnRIQue. 1966. Cartas privadas de Puebla del siglo XVI. Jahrbuch für Geschichte von Staat, Wirtschaft und Gesellschaft Lateinamerikas 3: 10-87.

Pérez Villanueva, Joaquín. 1986. Felipe IV y Luisa Enríquez Manrique de Lara, condesa de Paredes de Nava: un epistolario inédito. Salamanca: Caja de Ahorros y Monte de Piedad.

Redolar RiPOlL, Diego. 2014. Memoria manuscrita del siglo de oro en la Biblioteca Nacional. Madrid: Calambur Editorial, S.L.

Rodríguez Mateos, Joaquín. 2010. Un epistolario de Bernardo José Aldrete (1612-1623). Sevilla: Consejería de Cultura.

Rodríguez Morel, Genaro. 1995. Cartas privadas de Hernando Gorjón. Anuario de Estudios Americanos 52(2): 203-233.

RoJas, Elena. 2008. Documentos para la historia lingüística de Hispanoamérica. Siglo XVI. Madrid: Anejos del Boletín de la Real Academia Española, anejo 60.

Schmidt-Riese, Roland. 2002. Relatando México. Cinco textos del periodo fundacional de la Colonia en Tierra Firme. Madrid / Frankfurt am Main: Iberoamericana /Vervuert.

Stangl, Werner. 2012. Zwischen Authentizität und Fiktion. Die Korrespondenz spanischer Emigranten aus Amerika, 1492-1824. Colonia: Weimar.

Stoll, Eva. 2002. La memoria de Juan Ruiz de Arce. Madrid/Frankfurt am Main: Iberoamericana /Vervuert.

Stoll, Eva y María Nieves Vázquez. 2011. La conquista del Perú. Escritos y crónica de Alonso Borregán. Madrid / Frankfurt am Main: Iberoamericana /Vervuert.

Torres, CONCEPCión. 1995. Ana de Jesús, cartas. Salamanca: Universidad de Salamanca. 